\title{
Ink-Jet Printing: Perfect Tool for Cantilever Array Sensor Preparation for Microbial Growth Detection
}

\author{
G. Lukacs, N. Maloney, and M. Hegner \\ CRANN School of Physics, Trinity College Dublin, Dublin, Ireland \\ Correspondence should be addressed to G. Lukacs, lukacsg@tcd.ie \\ Received 15 June 2011; Accepted 22 August 2011 \\ Academic Editor: Maria Tenje
}

Copyright ( $) 2012$ G. Lukacs et al. This is an open access article distributed under the Creative Commons Attribution License, which permits unrestricted use, distribution, and reproduction in any medium, provided the original work is properly cited.

The use of microcantilever arrays for microbial growth detection provides a rapid and reliable technique for monitoring growth in industrial and clinical applications. Improving the reproducibility and sensitivity of this technique is of great importance. Ink-jet printing has been successfully used in microfabrication and biofabrication due to its high precision; however, only a few microbe-based applications have been reported. Here we demonstrate the advantages of its use for microcantilever based-growth sensing. Four microbial strains Escherichia coli, Staphylococcus aureus subsp. aureus, Pseudomonas aeruginosa, and Candida albicans were deposited and successfully grown on agarose-coated cantilevers by ink-jet printing. When compared to the capillary-coating method, ink-jet printing demonstrated more controlled cell deposition on cantilevers. The effect of various conditions on cell morphology was also investigated.

\section{Introduction}

The bioengineering fields of genomics, drug screening, tissue engineering, regenerative medicine, and various biosensor applications rely on biofabrication techniques which combine living and nonliving components deposited in a controlled manner. Bioprinting provides a rapid and reliable alternative to traditional methods giving the required spatial resolution for these applications [1]. Although biological structures are considered fragile, many studies have proven that ink-jet printing is feasible for a broad spectrum of biological material [2-6], and even more complex living systems such as cells can be deposited by this technique $[7,8]$. Drop-on-demand bioprinters use different mechanisms to force the "bio-ink" through a microfluidic chamber to the output orifice [1]. Thermal ink-jet printheads use a heating element to raise the temperature in the reservoir creating a bubble which then forces a small amount of ink through the output orifice. In a piezoelectric printhead, a piezo actuator is supplied with short electrical pulses which are converted into short pressure pulses. These pulses propagate through the liquid. Due to inertia forces and supported by surface tension, a small volume of liquid breaks off the liquid column to form a droplet. The droplet then flies freely with a velocity of $2-3 \mathrm{~m} / \mathrm{s}$. A pressure-driven printhead uses a pressure source behind the reservoir to produce a force on the liquid. A gate opens to allow ink to flow through the orifice [1]. It is clear that each of these approaches could damage the biomaterial by heat, electric field gradient, or pressure shock, and therefore, the range of working parameters must be optimised. Depending on the application, other issues such as nozzle clogging by cells or particles, aseptic printing, and aerosol formation have to be taken into account. Despite these problems, the spatial precision of the printed biomaterial renders these techniques highly advantageous for biosensing applications. Computer-controlled deposition offers a rapid functionalisation technique for micron-sized sensors such as cantilevers, quartz crystal microbalance (QCM), or surface plasmon resonance- (SPR) based sensing.

In this paper, we focus on microcantilever array functionalisation for cell-based sensor applications. Cantilever arrays operated in dynamic mode allow microbial growth analysis of various microbial cultures faster than conventional culturing techniques $[9,10]$. This biological sensor is based on oscillating cantilevers, where additional mass loading onto the cantilever surface results in a change of its 


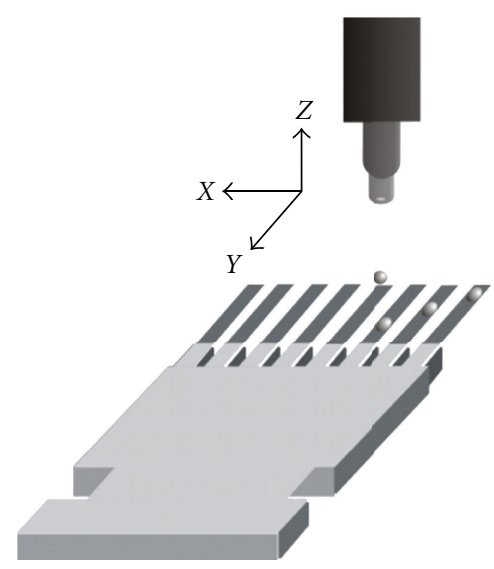

(a)

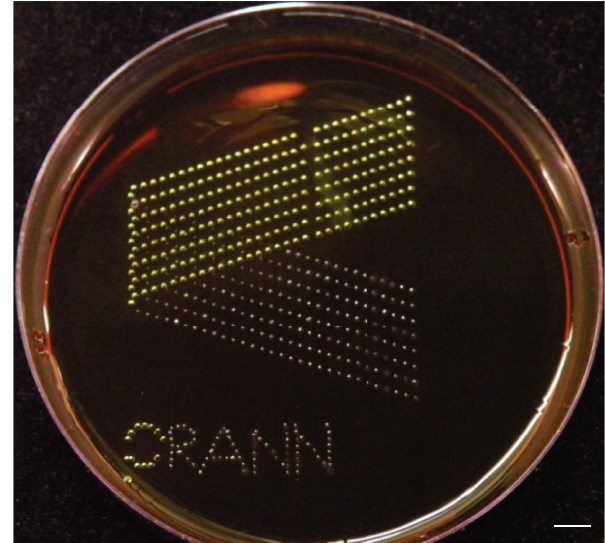

(b)

FIGURE 1: (a) Illustration of autodrop ink-jet spotting system for cantilever array functionalisation. Piezo-driven micropipette is mounted on a positioning system which has a positional accuracy of $1 \mu \mathrm{m}$ in all directions. (b) Viable E. coli cells are able to be inoculated by spotting on an agar plate in a controlled manner. The developing colonies form the CRANN Logo after an incubation of 18 hours at $35^{\circ} \mathrm{C}$. Scale bar $5 \mathrm{~mm}$. The different optical appearance of the individual E. coli colonies spotted is a result of different rates of metabolism which lead to different colouring.

resonance frequency. Ramos et al. demonstrated [11] that the response of nanomechanical resonators depends on both the position and the stiffness of adsorbed biological material on the cantilever surface. This is important for the achievable sensitivity of the technique. Here we introduce the use of ink-jet printing for the functionalisation of cantilevers with industry-relevant microbial species for growth detection.

\section{Materials and Methods}

2.1. Chemicals, Cultures. Chemicals and culturing media were purchased from Sigma Aldrich (Arklow, Ireland) unless otherwise stated. The following microbial strains were obtained from Collection de l'Institut Pasteur (Paris, France): Escherichia coli CIP 53.126 (E. coli), Pseudomonas aeruginosa CIP 82.118 (P. aeruginosa), Staphylococcus aureus subsp. aureus CIP 4.83 (S. aureus), and Candida albicans CIP 48.72 (C. albicans). Bacterial and C. albicans strains were maintained on $\mathrm{LB}(0.5 \% \mathrm{NaCl}, 0.5 \%$ yeast extract, $1 \%$ tryptone) or potato dextrose agar (PDA) slants, respectively, and stored at $4^{\circ} \mathrm{C}$. Overnight cultures were prepared $\left(200 \mathrm{rpm}, 35^{\circ} \mathrm{C}, 15-18 \mathrm{~h}\right)$ from single colonies of each organism. The following day, $1 \mathrm{~mL}$ of the overnight cultures was transferred into $30 \mathrm{~mL}$ of LB or malt extract broth (ME) for bacterial or fungal cultures respectively, and cultured $\left(200 \mathrm{rpm}, 35^{\circ} \mathrm{C}\right)$ for $110 \mathrm{~min}$ in order to reach a logarithmic growth rate. One $\mathrm{mL}$ of each culture was precipitated by centrifugation (10000 rpm, $5 \mathrm{~min}$, Genofuge $16 \mathrm{M}$, Techne) and resuspended in $0.5 \mathrm{~mL}$ of the tested medium (LB, $10 \%$ $\mathrm{LB}, \mathrm{ME}, 10 \% \mathrm{ME}$, or deionised water). Cell concentrations of the cultures were determined using cell counting chambers and optical microscopy.

2.2. Cantilever Preparation. Cantilever arrays were obtained from the IBM Zurich Research Laboratory (Zurich, Switzerland). Each array has 8 cantilevers with a length of $500 \mu \mathrm{m}$, width of $100 \mu \mathrm{m}$, and thickness of $2-7 \mu \mathrm{m}$ with a pitch of $250 \mu \mathrm{m}$. In preparation for microbial coating, the arrays were cleaned using $\mathrm{O}_{2}$ plasma $(0.3 \mathrm{mbar}, 3 \mathrm{~min}$, PICO Barrel Asher: Diener electronic GmbH and Co. KG, Ebhausen, Germany) and silanised for $45 \mathrm{~min}$ (1\% (3-glycidyloxypropyl)trimethoxysilane, $1 \% \mathrm{~N}$-ethyldiisopropylamine in water-free toluene). The epoxy-silanised arrays were washed in waterfree toluene $(2 \times 15 \mathrm{~min})$ and dried in $\mathrm{N}_{2}$ and subsequently coated with $1 \%(\mathrm{wt} / \mathrm{vol})$ agarose-water solution (SeaKem Gold Agarose, Bioconcept; NH, USA) by using preheated $\left(>100^{\circ} \mathrm{C}\right)$ glass microcapillaries (King Precision Glass Inc., Calif, USA). The $\mathrm{pH}$ of the melted agarose was adjusted to $\mathrm{pH} 11.9$ by adding $2 \mathrm{M} \mathrm{NaOH}$ to the solution. The cantilevers were incubated in the agarose-filled capillaries for 5 seconds. Using this method a thin agarose layer is formed on the cantilever surface. The boundary of this gel layer is visible on the images of each cantilever.

2.3. Capillary Coating. As a control experiment, cantilevers were functionalised with microbes using glass microcapillaries. Agarose-coated cantilevers were immersed to full, half and $1 / 5$ of their lengths for 6, 4, and 2 minutes, respectively, (Figure 2(a)). Capillary tubes were loaded with E. coli suspension $\left(10 \% \mathrm{LB}, 2.49 \times 10^{8}\right.$ cells $\left./ \mathrm{mL}\right)$.

2.4. Ink-Jet Spotting. The MD-P-801 autodrop dispensing system (Microdrop, Norderstedt, Germany) is comprised of a piezo-driven pipette $(\mathrm{AD}-\mathrm{K}-501)$ and is mounted on a three axis micropositioning system which has an accuracy of $1 \mu \mathrm{m}$ in all directions (Figure 1). The nozzle diameter used was $50 \mu \mathrm{m}$. The volume of liquid deposited is not only dependant on its viscosity but also on the voltage and the pulse length applied on the piezo actuator. In order to deposit one droplet per pulse, these parameter settings have to be adjusted for each individual suspension prior to 


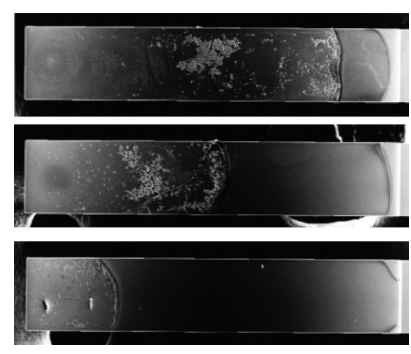

(a)

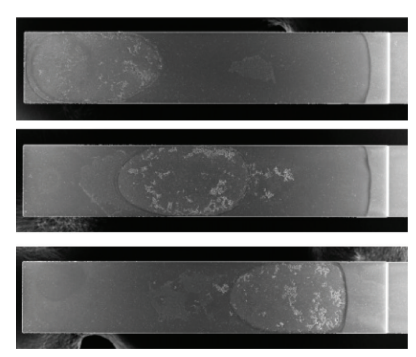

(b)

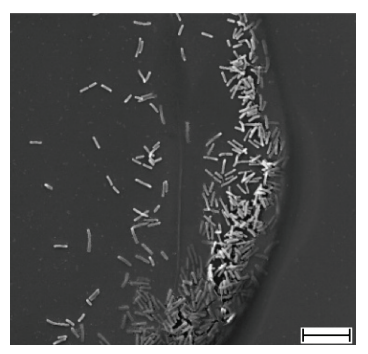

(c)

FIGURE 2: (a) SEM images of capillary-coated cantilevers for full (top), half (medium), and 1/5 (bottom) immersion in E. coli suspension. (b) Ten drops of $E$. coli suspension were deposited at different positions along the cantilevers' longitudinal axis. Cantilever arrays in images (a) and (b) were incubated for $24 \mathrm{~h}$ at optimal growth conditions before SEM imaging. The width of the cantilevers is $100 \mu \mathrm{m}$. The used suspension $\left(2.49 \times 10^{8}\right.$ cells $\left./ \mathrm{mL}\right)$ was prepared in $10 \%$ LB. (c) SEM image showing accumulation of E. coli cells at the front end of capillary tube after functionalisation. Scale bar $10 \mu \mathrm{m}$.

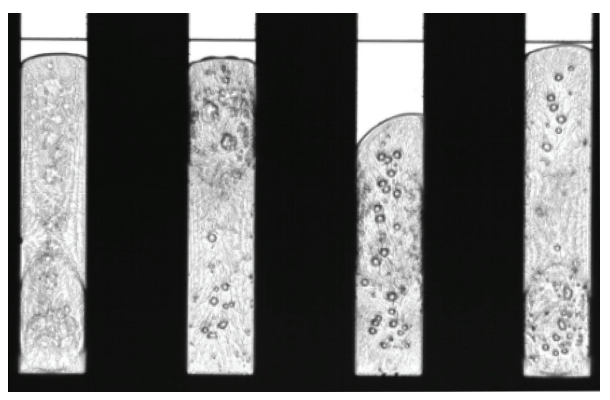

(a)

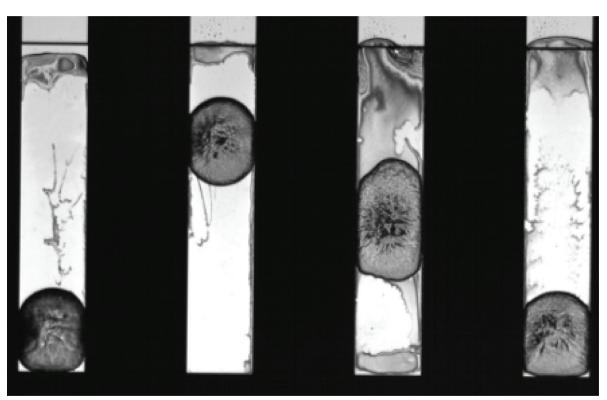

(c)

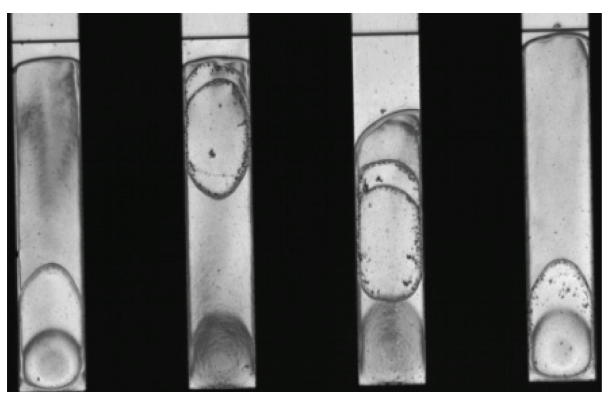

(b)

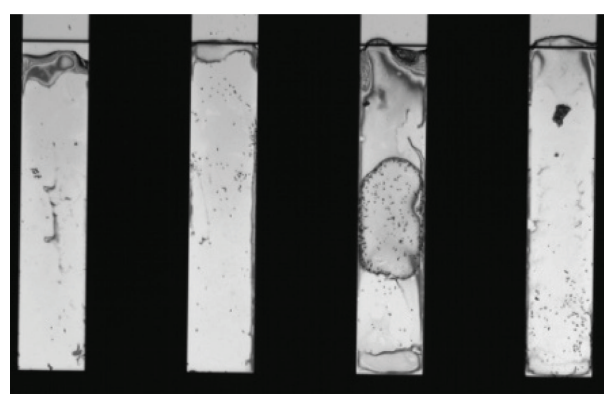

(d)

Figure 3: Optical microscope images of cantilevers with widths of $100 \mu \mathrm{m}$. Ten drops of E. coli suspension $\left(2.49 \times 10^{8}\right.$ cells $\left./ \mathrm{mL}\right)$ were deposited at different positions on the cantilevers. (a) Cantilever array was incubated at growth conditions before image was taken. (b) Array was incubated at growth conditions then glutaraldehyde fixation (see Materials and Methods section) of the sample was carried out. (c) Array was dried at room conditions after deposition of cells (nongrowth control) (d) Array was prepared as a nongrowth control, then glutaraldehyde fixation was carried out.

deposition. The final spot diameter depends on the surface tension of the printed material and on the surface on which it is deposited. By using a low pulse frequency in our experiments we allowed each droplet to soak into the agarose surface before the next droplet landed on the surface. With this method, aerosol formation could be prevented, and; therefore, no cross-contamination between the cantilevers is expected. The micropipette was cleaned 3 times with $70 \%$ ethanol solution and twice with $96 \%$ ethanol solution before use. These cleaning steps were sufficient to avoid nozzle clogging or cross-contamination. Cell suspensions prepared as mentioned previously were loaded into 96-well microtiter plates (Sterilin Ltd., Norwick, UK). Prior to filling the micropipette, solutions in the microtiter plate reservoirs were mixed in order to provide an even cell concentration in the nozzle. Droplets of the different suspensions were spotted on each cantilever independently. To avoid crosscontamination of the lever surfaces the nozzle was cleaned with ethanol between each tested suspension.

\subsection{Scanning Electron Microscopy (SEM) Sample Preparation.} The cell-functionalised cantilever arrays were exposed to relatively dry room conditions $(20-40 \% \mathrm{RH})$ for less than 30 minutes. For growth testing, they were placed in high 
TABle 1: Calculation of drop volume after deposition of 180 droplets of microbe suspensions.

\begin{tabular}{lccc}
\hline Cells/mL & $\begin{array}{c}\text { Total cell } \\
\text { number/180 drops }\end{array}$ & $\begin{array}{c}\text { Drop volume } \\
(\mathrm{L})\end{array}$ & $\begin{array}{c}\text { Average cell } \\
\text { number/drop }\end{array}$ \\
\hline $6.3 \times 10^{6}$ & 226 & $1.99 \times 10^{-10}$ & 1.25 \\
$1.175 \times 10^{6}$ & 45 & $2.13 \times 10^{-10}$ & 0.25 \\
$\sim 6.3 \times 10^{5}$ & 18 & $1.59 \times 10^{-10}$ & 0.1 \\
\hline
\end{tabular}

humidity ( $>95 \% \mathrm{RH})$ at $35^{\circ} \mathrm{C}$. For nongrowth controls, they were left to dry completely at room conditions. High humidity during growth testing was provided by a small water reservoir placed closed to the arrays in a closed Petri dish.

Prior to SEM imaging, cantilever arrays were dried at $24^{\circ} \mathrm{C}$ and $35 \% \mathrm{RH}$ for at least $24 \mathrm{hrs}$. Cantilever arrays were immersed in $5 \%$ glutaraldehyde solution $(0.05 \mathrm{M}$ phosphate buffer, $\mathrm{pH} 7$ ) and incubated at room conditions with gentle shaking for 3-4h. After fixation, excess glutaraldehyde was removed by washing in phosphate buffer $(0.05 \mathrm{M}, \mathrm{pH} 7)$ for $10 \mathrm{~min}$. This step was repeated 6 times. Samples were subsequently dehydrated using 10-30-50-70-90-100-100\% ethanol solution (10 minutes for each step). After drying, $10 \mathrm{~nm}$ Pd was deposited on the samples (Cressington Sputter Coater 208 HR Watford, United Kingdom). SEM images (SEM-ULTRA, Carl Zeiss, Germany) were taken at $5 \mathrm{kV}$, with an aperture size of $30,000 \mu \mathrm{m}$ using the lens detector.

\section{Results and Discussion}

Microcantilever arrays were previously used to detect the viable growth of $E$. coli $[10,12]$ and Aspergillus niger ( $A$. niger) $[9,13]$. In these studies individual glass microcapillaries were used to seed cells on individual agarosefunctionalised cantilevers. The deposition of $A$. niger spores was performed by functionalising the cantilever surface with a uniform distribution of Aspergillus-specific antibodies. The seeded microbial species were mixed with a culture medium which provided essential nutrition for microbial growth. After immersion of the levers in the suspension, nutrition is stored in the porous agarose layer. During growth microbes assimilate nutrition and water from the nutritive layer and humid air. In order to compare the coating efficiency of ink-jet printing to that of the previously used capillary coating method, two cantilever arrays were prepared for growth testing (Figure 2). Agarose-coated cantilevers were immersed to full, half, and 1/5 of their lengths in glass capillaries filled with E. coli suspension for 6, 4, and 2 minutes, respectively, (Figure 2(a)). On a second agarosecoated array the same $E$. coli suspension was deposited by spotting at different points along the cantilever. At each position, 10 drops of cell suspension were dispensed with high accuracy (Figure 2(b)). SEM images of E. coli colonies were taken after $24 \mathrm{~h}$ growth. As a control, a second set of arrays were prepared as described above; however, they were not incubated at optimal growth conditions (non growth controls). Capillary coating with these relatively large

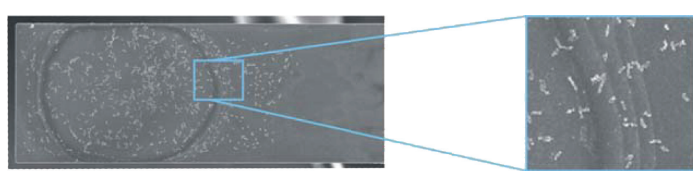

(a)

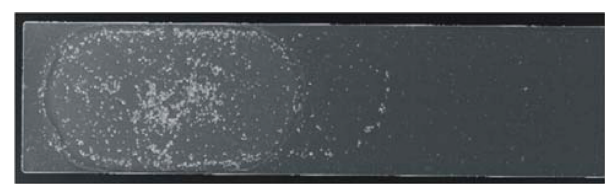

(b)

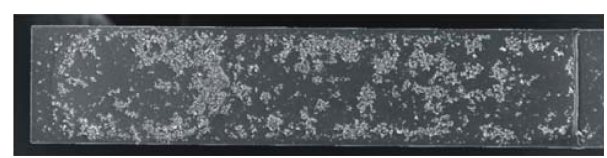

(c)

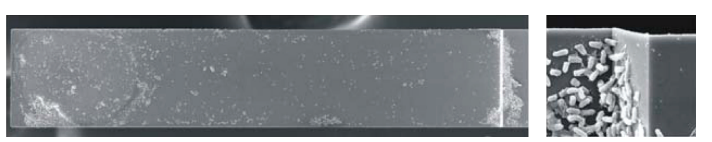

(d)

FIGURE 4: SEM images of cantilevers demonstrating accuracy of drop positioning and cell distribution after $24 \mathrm{~h}$ incubation at growth conditions. The width of cantilevers is $100 \mu \mathrm{m}$ in each case. Ten drops of cell suspension were deposited at the front end of the cantilevers. (a) Imprints of series of droplets on agarose-coated cantilever, after growth of $P$. aeruginosa. (b) Ten perfectly spotted drops of $S$. aureus $\left(2.92 \times 10^{8}\right.$ cells/mL, $10 \%$ LB $)$ cells on an agarosecoated cantilever. One spot was deliberately deposited off-position. (c) S. aureus $\left(3.28 \times 10^{8}\right.$ cells $\left./ \mathrm{mL}, \mathrm{LB}\right)$ growth on cantilever surface. (d) P. aeruginosa $\left(1.84 \times 10^{8}\right.$ cells $\left./ \mathrm{mL}, 10 \% \mathrm{LB}\right)$ growth on cantilever surface. Cells are growing over the clamping point of the cantilever.

structures $(2 \mu \mathrm{m})$ results in the accumulation of cells at the capillary open end. This can be explained by the flow of cells with the liquid and evaporation at the front of the tube (Figure 2(c)). Compared to capillary functionalisation, the localised deposition of cells can be easily controlled by ink-jet printing. The sharp edge of the drop boundary visible on the SEM image (Figure 2(b)) shows that the positional accuracy of the delivered droplet is highly reproducible. Deposition of 180 droplets with 3 different dilutions of microbe suspension shows that the average droplet size and the average cell number per droplet correlate with the dilution of the samples (Table 1). There was no increase in the cell number per drop which indicates that cells are not sedimenting in the nozzle during deposition. The optimal cell number to avoid nozzle clogging in the case of bacteria is under $5-6 \times 10^{8} \mathrm{cfu}$ and under $1.2-1.4 \times 10^{6} \mathrm{cfu}$ in the case of $C$. albicans. It is important to mention that before glutaraldehyde fixation of samples, salt and medium residues covered the cantilevers indicating good diffusion of the nutrition along the full length of the lever. The washing and dehydration steps after glutaraldehyde fixation were sufficient to remove these residues without the removal of the deposited cells (Figure 3). We postulate that the thin liquid layer present at $>90 \%$ relative humidity may act to keep the nutrition 


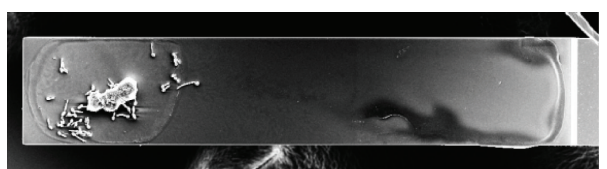

(a)

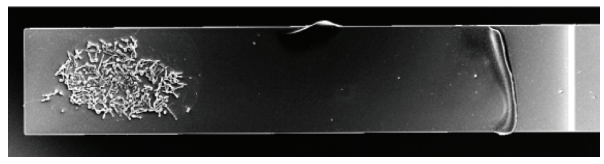

(c)

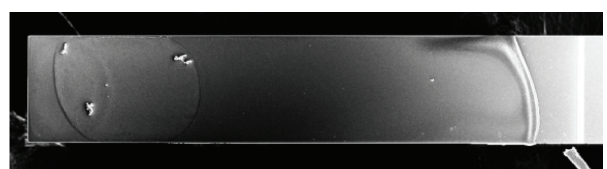

(b)

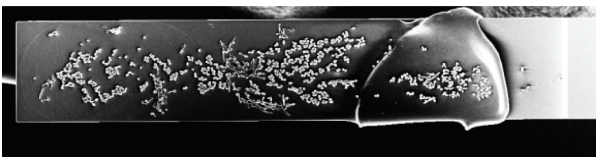

(d)

Figure 5: SEM images of cantilevers showing C. albicans propagation on the surface after $24 \mathrm{~h}$ incubation at growth conditions. The width of cantilevers is $100 \mu \mathrm{m}$ in each case. Ten drops of cell suspensions were deposited at the front end of the cantilevers. (a, c) C. albicans $\left(1.36 \times 10^{6}\right.$ cells $\left./ \mathrm{mL}, 10 \% \mathrm{ME}\right)$ before growth (a) after growth (c). (b, d): C. albicans $\left(10^{6} \mathrm{cells} / \mathrm{mL}, \mathrm{ME}\right)$ before growth (b) after growth (d).

Candida albicans
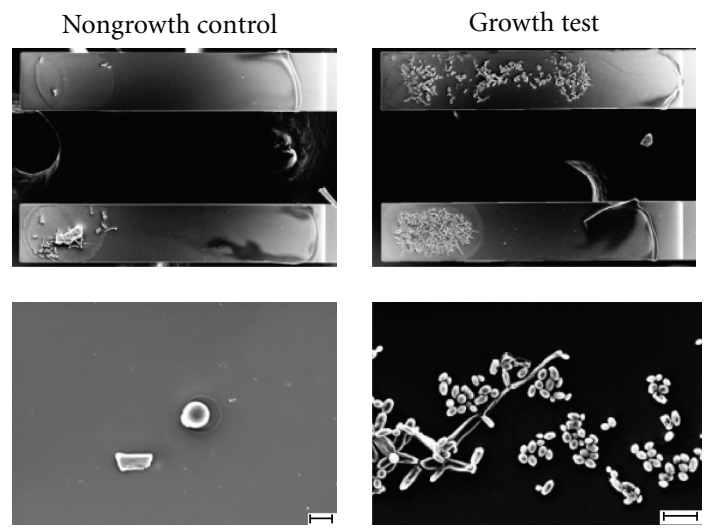

(a)

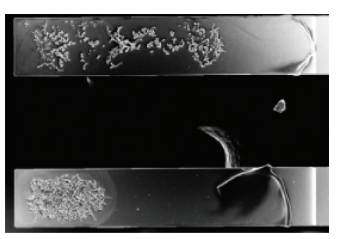

Pseudomonas aeruginosa
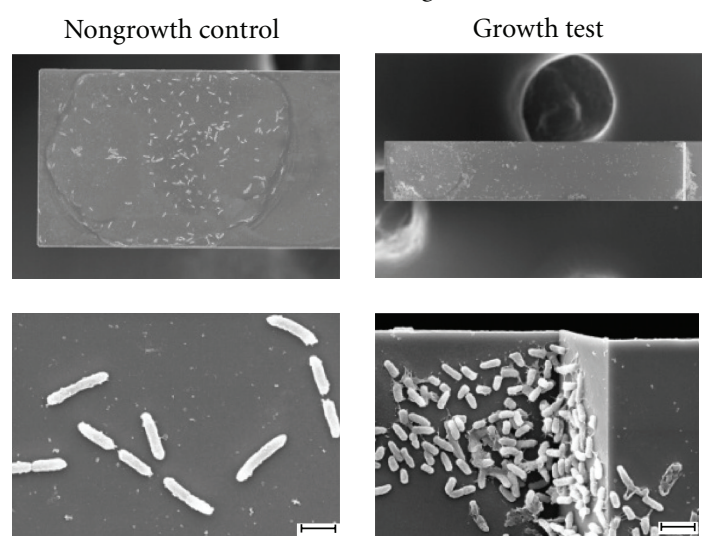

(c)
Escherichia coli

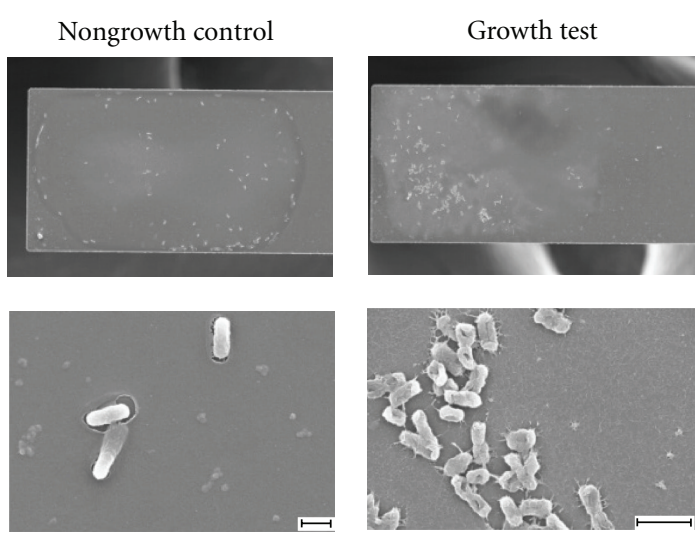

(b)

Staphylococcus aureus

Nongrowth control
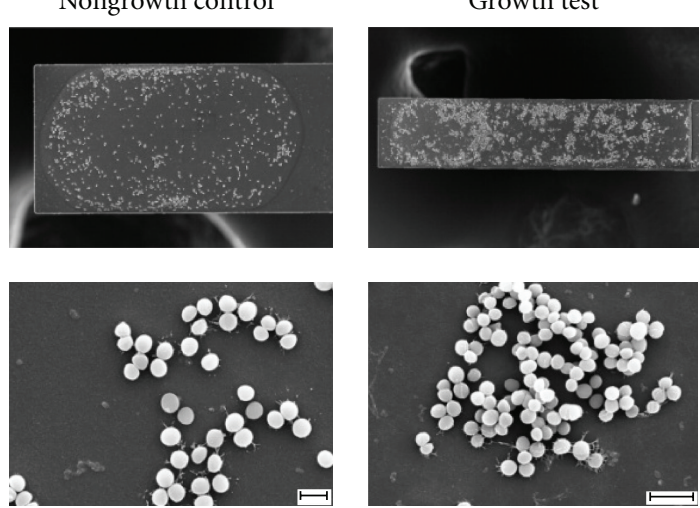

(d)

Figure 6: SEM images of growing microbe cultures on agarose-coated cantilevers. The width of cantilevers is $100 \mu \mathrm{m}$. In each section, the pictures on the left show the surface of the cantilevers dried at room conditions after ink-jet spotting. The pictures on the right show cantilevers after $24 \mathrm{~h}$ incubation at growth conditions. Ten droplets were deposited on the front end of each cantilever. (a) C. albicans suspensions deposited on the front end of two cantilevers (top: $1.36 \times 10^{6}$ cells $/ \mathrm{mL}, 10 \% \mathrm{ME}$, bottom: $10^{6}$ cells $/ \mathrm{mL}, \mathrm{ME}$ ). Scale bars $10 \mu \mathrm{m}$. C. albicans grow pseudohypha on the surface (bottom right) (b) E. coli suspension $\left(3.96 \times 10^{8}\right.$ cells $\left./ \mathrm{mL}, 10 \% \mathrm{LB}\right)$. Scale bars: bottom left $1 \mu \mathrm{m}$, bottom right $2 \mu \mathrm{m}$. (c) P. aeruginosa $\left(1.84 \times 10^{8}\right.$ cells $\left./ \mathrm{mL}, 10 \% \mathrm{LB}\right)$. Scale bars $2 \mu \mathrm{m}$; (d) S. aureus suspension $\left(2.92 \times 10^{8}\right.$ cells $/ \mathrm{mL}, 10 \%$ LB). Scale bars: bottom left $1 \mu \mathrm{m}$, bottom right $2 \mu \mathrm{m}$. 


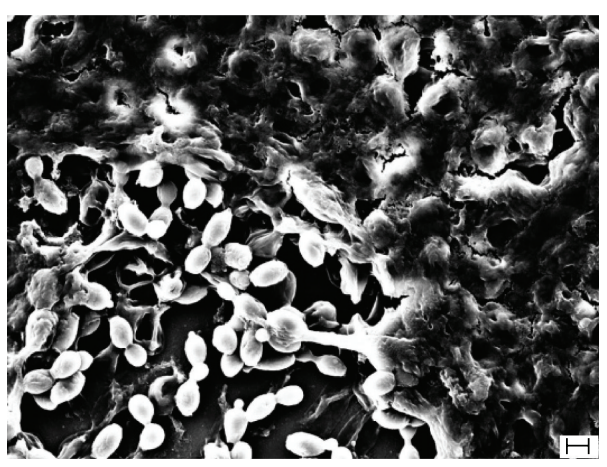

(a)

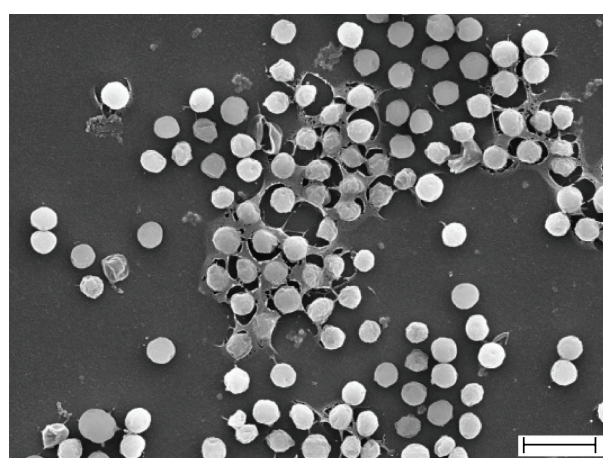

(b)

Figure 7: SEM images of biofilm-like structures of C. albicans (a) and S. aureus (b) on a cantilever surface. C. albicans cells were deposited in $10 \% \mathrm{ME}$ medium $\left(10^{6}\right.$ cells $\left./ \mathrm{mL}\right)$ and incubated at growth conditions for $24 \mathrm{~h}$. S. aureus cells were deposited in $10 \% \mathrm{LB}$ medium $(2.92 \times$ $10^{8}$ cells $/ \mathrm{mL}$ ) and incubated at growth conditions for $24 \mathrm{~h}$.

in solution on the cantilever surface which aids in this distribution. Therefore, in an actual growth measurement, at high humidity, no salt-carbohydrate-protein crystal layer is formed which would have an effect on the mechanical properties of these sensors and the growth characteristics of the seeded microorganisms. This provides an opportunity for initial cells to spread along the surface even if nutrition is originally available only at the spotting site at the beginning of the experiment. A similar distribution of nutrition is not seen on the non-growth control cantilever which was not incubated at elevated humidity levels. In some experiments Figures $4(\mathrm{c})$ and $4(\mathrm{~d})$, cells were observed outside the spotting area after growth of the culture which cannot be explained by an off-position droplet deposited during inkjet printing (Figure 4(b)). Concentric imprints caused by individual droplets on the agarose layer are often visible on SEM images showing an accurate centre position of the droplets (Figure 4(a)). The tested C. albicans (Figure 5) or $S$. aureus (Figure 4(c)) cannot actively move away from their original position while E. coli or P. aeruginosa (Figure $4(\mathrm{~d})$ ) are motile bacteria enabling cell propagation especially if a thin liquid layer is available. This propagation is more likely if $100 \%$ culturing medium is used for microbe deposition instead of with diluted medium (10\% LB or $10 \% \mathrm{ME})$. Dilution of the growth medium decreased the growth rate of microbes. In the case of $C$. albicans, the use of less cells per droplet (5-10 cells/droplet) in full medium still resulted in the complete coverage of the cantilever surface with cells (Figure 5(d)) when compared to the non-growth control (Figure 5(b)). Spotting 50-100 cells in diluted medium (Figures 5(a), 5(c)) did not allow the organism to grow out of their initial spotted position. In several experiments, four microbial strains were tested in terms of viability after inkjet printing and grown on the surfaces of microcantilevers. Each array was prepared twice, and one of each was used as a non-growth control. SEM images of these experiments show the viability and multiplication of the tested organisms (Figure 6). In each case, elevated cell numbers can be observed on the arrays exposed to growth conditions (high humidity and elevated temperature). Candida albicans is a yeast form microfungi with typical cell dimensions of 4-5 $\mu \mathrm{m}$ in diameter. At certain conditions, mostly related to limited nutrition, they are able to grow pseudohypha where the cells have not separated after cell division. This morphological switch is often studied as it has a major role in $C$. albicans pathogenicity [14]. In our tests, C. albicans cells were seeded in the budding-yeast form in $100 \% \mathrm{ME}$ suspension and also 10\% ME suspension. Figure 6(a) shows that in the suspension with full medium some cells are developing filamentous structures (pseudohyphae) but also budding-yeast form can also be observed. It is likely that in this special microenvironment the pseudohyphae play a part in the spread of Candida along the cantilevers. All these processes resulting in the colonisation of the surface might cause changes in the cantilevers mechanical properties, and; hence, influence growth detection measurements which are originally based on the detection of a mass increase on the cantilever surface. For some biosensing techniques, high salt or sugar content of microbial culturing medium can disturb the measurement although decreasing the available nutrients in the environment can cause changes in growth rate or morphology of the cells. In other experiments C. albicans (Figure 7(a)) and S. aureus (Figure 7(b)) cells were deposited on agarose-coated cantilevers with diluted medium. We found that decreasing nutrition in the used suspension results in a decrease in viability and also altered the morphology of the cells. Cells started to accumulate extracellular biomaterial which resembled biofilm formation (Figure 7). Bacteria and Candida colonies usually form biofilms on various surfaces including silicon in order to help the bacterial population to survive in certain environments. However, further investigation has to be done to understand this process in the case of microcantilevers. It is expected that biofilm formation will influence the spring constant (k) of a cantilever. It is also important to mention that the use of deionised water for cell deposition resulted in the centering of bacterial cells with respect to droplet positions, while the use of more viscous suspensions, such as culture medium, resulted in the accumulation of cells around 
the rim of the liquid droplet, thus, allowing for high accuracy when positioning microorganisms within a droplet (data not shown).

\section{Conclusion}

It was successfully proved in our experiments that different types of microbial cells are able to be deposited on microcantilever surfaces while retaining their viability. Ink-jet spotting was used for cantilever functionalisation with viable cells, thus, revealing its potential as a superior alternative for sensor applications and real-time growth measurements. There is no need for specific antibodies facilitating tight binding during deposition of cells. In the case of motile microorganisms the fluid film allows cells to be freely distributed, and, in these cases the introduction of antibodies could keep the species in place. Compared to the previously reported capillary-coating technique ink-jet printing has been shown to be a more accurate way to position cells, and hence, to optimise the detection of mass changes during microcantilever-based growth detection.

\section{Acknowledgments}

This work was supported by the Science Foundation Ireland under the CSET scheme SFI08/CE/I1432. The high resolution imaging work was enabled by the CRANN Advanced Microscopy Laboratory (AML), Trinity College Dublin.

\section{References}

[1] K. W. Binder, A. J. Allen, J. J. Yoo, and A. Atala, "Drop-ondemand inkjet bioprinting: a primer," Gene Therapy and Regulation, vol. 6, no. 1, pp. 33-49, 2011.

[2] T. Braun, N. Backmann, A. Bietsch et al., "Conformational change of bacteriorhodopsin quantitatively monitored by microcantilever sensors," Biophysical Journal, vol. 90, no. 8, pp. 2970-2977, 2006.

[3] T. Braun, M. K. Ghatkesar, N. Backmann et al., "Quantitative time-resolved measurement of membrane protein-ligand interactions using microcantilever array sensors," Nature $\mathrm{Na}$ notechnology, vol. 4, no. 3, pp. 179-185, 2009.

[4] T. Okamoto, T. Suzuki, and N. Yamamoto, "Microarray fabrication with covalent attachment of DNA using Bubble Jet technology," Nature Biotechnology, vol. 18, no. 4, pp. 438-441, 2000.

[5] A. Roda, M. Guardigli, C. Russo, P. Pasini, and M. Baraldini, "Protein microdeposition using a conventional ink-jet printer," BioTechniques, vol. 28, no. 3, pp. 492-496, 2000.

[6] A. Bietsch, J. Zhang, M. Hegner, H. P. Lang, and C. Gerber, "Rapid functionalization of cantilever array sensors by inkjet printing," Nanotechnology, vol. 15, no. 8, pp. 873-880, 2004.

[7] T. Xu, S. Petridou, E. H. Lee et al., "Construction of highdensity bacterial colony arrays and patterns by the ink-jet method," Biotechnology and Bioengineering, vol. 85, no. 1, pp. 29-33, 2003.

[8] T. Xu, J. Jin, C. Gregory, J. J. Hickman, and T. Boland, "Inkjet printing of viable mammalian cells," Biomaterials, vol. 26, no. 1, pp. 93-99, 2005.

[9] N. Nugaeva, K. Y. Gfeller, N. Backmann et al., "An antibodysensitized microfabricated cantilever for the growth detection of Aspergillus niger spores," Microscopy and Microanalysis, vol. 13, no. 1, pp. 13-17, 2007.

[10] K. Y. Gfeller, N. Nugaeva, and M. Hegner, "Rapid biosensor for detection of antibiotic-selective growth of Escherichia coli," Applied and Environmental Microbiology, vol. 71, no. 5, pp. 2626-2631, 2005.

[11] D. Ramos, J. Tamayo, J. Mertens, M. Calleja, and A. Zaballos, "Origin of the response of nanomechanical resonators to bacteria adsorption," Journal of Applied Physics, vol. 100, no. 10, Article ID 106105, 2006.

[12] K. Y. Gfeller, N. Nugaeva, and M. Hegner, "Micromechanical oscillators as rapid biosensor for the detection of active growth of Escherichia coli," Biosensors and Bioelectronics, vol. 21, no. 3, pp. 528-533, 2005.

[13] N. Nugaeva, K. Y. Gfeller, N. Backmann, H. P. Lang, M. Düggelin, and M. Hegner, "Nanomechanical cantilever array sensors for selective fungal immobilization and real-time growth detection," Biosensors and Bioelectronics, vol. 21, pp. 849-856, 2005.

[14] I. A. Cleary, P. Mulabagal, S. M. Reinhard et al., "Pseudohyphal regulation by the transcription factor Rfglp in Candida albicans," Eukaryotic Cell, vol. 9, no. 9, pp. 1363-1373, 2010. 

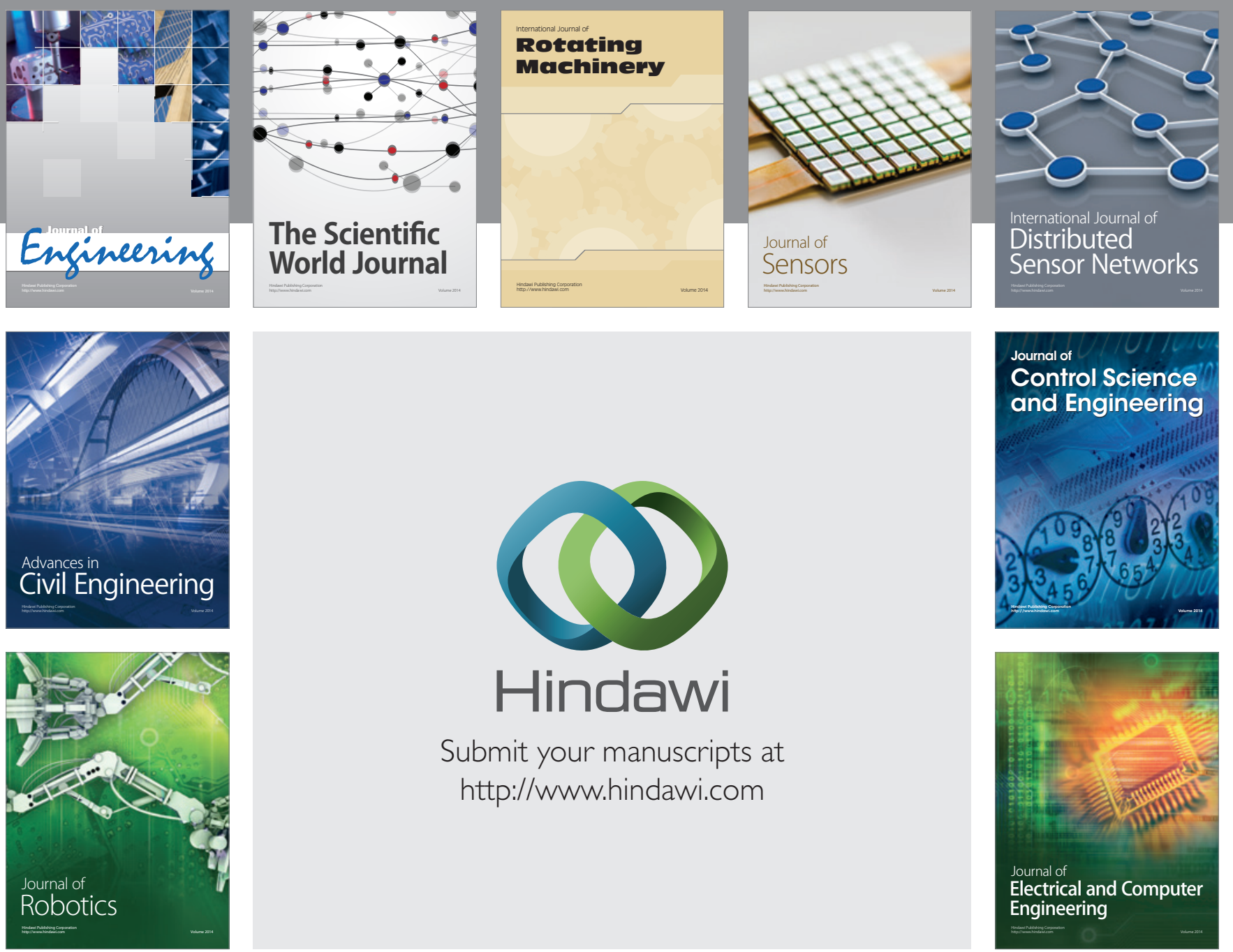

Submit your manuscripts at

http://www.hindawi.com
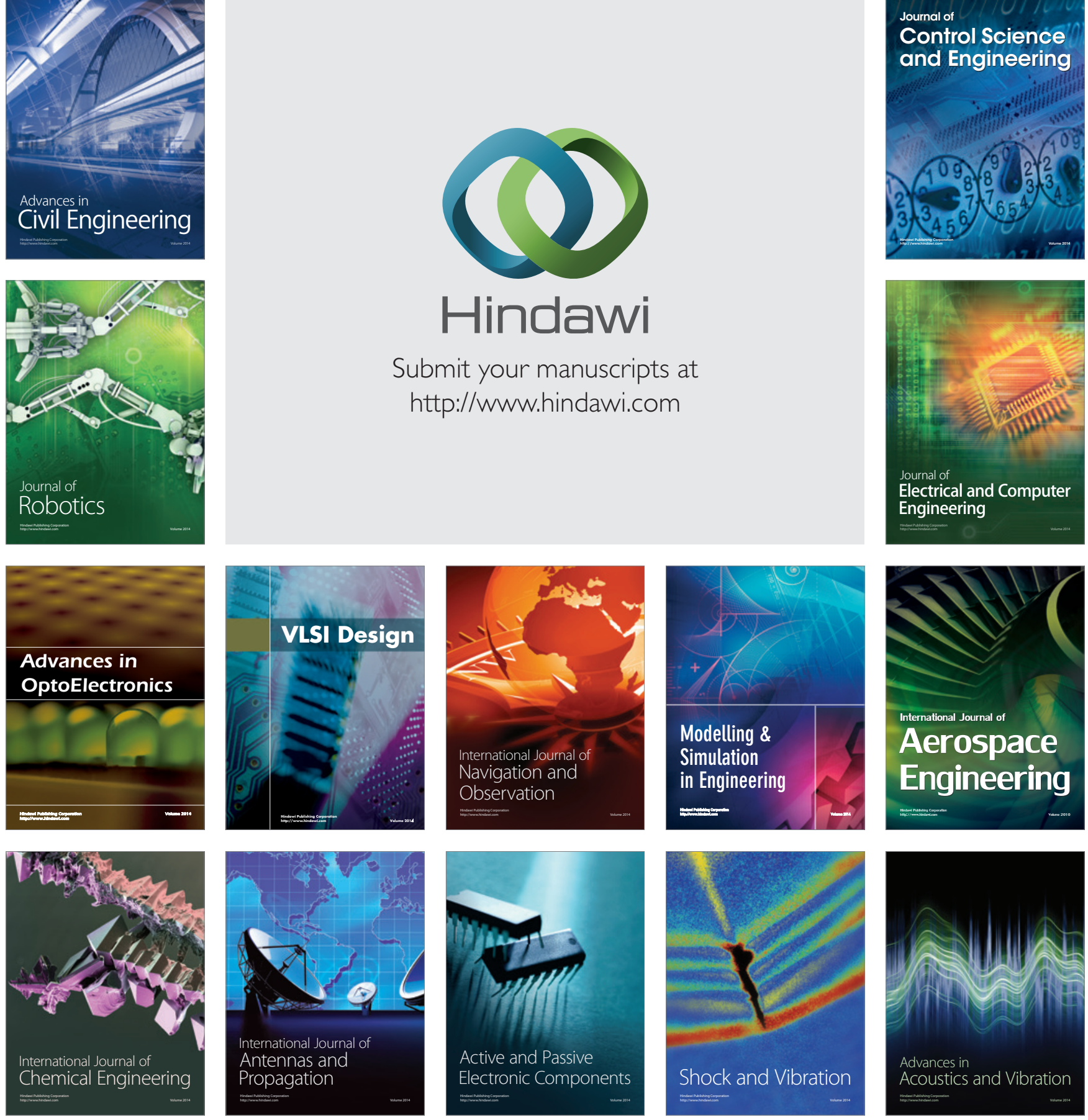